\title{
Redescription of Pylocheles (Bathycheles) cubensis Ortiz \& Gómez, 1986, the senior synonym of Pylocheles (B.) chacei Forest, 1987 (Decapoda, Anomura, Paguroidea, Pylochelidae)
}

\author{
PATSY A. MCLAUGHLIN ${ }^{1}$, RAFAEL LEMAITRE ${ }^{2} \&$ MANUEL ORTIZ $^{3}$ \\ ${ }^{1}$ Shannon Point Marine Center, Western Washington University, 1900 Shannon Point Road, Anacortes, WA 98221-9081B, U.S.A . \\ (hermit@fidalgo.net) \\ ${ }^{2}$ Smithsonian Institution, National Museum of Natural History, Department of Invertebrate Zoology, P.O. Box 37012, Washington, D. \\ C. 20013-7012, U.S.A. (lemaitrr@si.edu) \\ ${ }^{3}$ Centro de Investigaciones Marinas, Universidad de La Habana, Calle 16 \# 114 entre $1^{r a}$ y $3^{r a}$, Miramar, Playa, C. Habana, CUBA. \\ (ortiztouzet@yahoo.com)
}

\begin{abstract}
A reexamination of the holotypes of Pylocheles cubensis Ortiz \& Gómez, 1986 and Pylocheles (Bathycheles) chacei Forest, 1987 has shown that these two deep-water taxa are identical. Pylocheles cubensis is the senior synonym and is assigned to the subgenus Bathycheles Forest, 1987, replacing P. (B.) chacei as the single Western Atlantic representative of the subgenus. Pylocheles (Bathycheles) cubensis is redescribed and illustrated.
\end{abstract}

Key words: Anomura, Paguroidea, Pylochelidae, Pylocheles, Bathycheles, P. (B.) cubensis, P. (B.) chacei, deep-water, Western Atlantic

\section{Introduction}

In the little known Cuban journal Revista de Investigaciones Marinas, Ortiz \& Gómez (1986) described a new species of the paguroid genus Pylocheles A. Milne-Edwards, 1880, collected during the Joint Soviet-Bulgarian-Cuban Expedition in deep waters off the southern coast of Cuba. To the four species of the genus known at the time, Pylocheles miersi Alcock \& Anderson, 1899 and P. rigidus Yokoya, 1933 from the Indo-Pacific, and P. agassizii A. Milne-Edwards, 1880 and P. partitus Benedict, 1901 from the western Atlantic, Ortiz \& Gómez (1986) added P. cubensis Ortiz \& Gómez, 1986, and presented a key to the species of the genus. The description of $P$. cubensis may have gone unnoticed by the majority of the scientific community, not only because of the limited circulation of the journal, but also because the genus was inadvertently and incorrectly assigned to the superfamily Galatheoidea.

The following year, Forest's (1987) monographic revision of the family Pylochelidae was published, in which he divided the genus Pylocheles into three subgenera, Pylocheles A. Milne-Edwards, 1880, Xylocheles Forest, 1987, and Bathycheles Forest, 1987. Additionally, Forest placed P. rigidus in synonymy with $P$. (P.) mortenseni Boas, 1926 and P. partitus in synonymy with P. (P.) agassizii. To the subgenus Bathycheles, Forest (1987) assigned Cheiroplatea macgilchristi Alcock, 1905 and described five new species, four from the IndoPacific and $P$. (B.) chacei Forest, 1987 from the Western Atlantic. The latter species, based on a single damaged female, exhibited two characters that set it apart from all other members of the subgenus, i.e., the quadrate notch in the posterior margin of the sixth pleonal tergite and the presence of two membranous circular patches on the dorsal surface of the anterior lobe of the telson. Although Ortiz \& Gómez (1986) made no men- 
tion of membranous patches on the telson, in their key, they had differentiated their P. cubensis from P. miersi by the quadrate notch on the sixth tergal margin in their taxon. Considering the generally close proximity of the type localities of $P$. cubensis, south of Cuba, and $P$. (B.) chacei, Turks \& Caicos Islands, north of Haiti, and the similarly notched pleonal margins, the present authors decided to critically compare the two taxa. As a result, $P$. (B.) chacei was found to be the junior synonym of $P$. cubensis and the latter appropriately assigned to the subgenus Bathycheles. As the descriptions of both taxa were incomplete, a composite redescription of this species, together with photographs of the male holotype, is presented.

The holotype of $P$. (B.) cubensis was originally deposited in the Instituto de Oceanología de la Academia de Ciencias de Cuba, Havana (IDO), but was transferred to the collections of Acuario Nacional de Cuba (ANC); it is missing the dactyl of the right cheliped, and distal three segments of the right third pereopod. The holotype of $P$. (B.) chacei is deposited in the National Museum of Natural History, Smithsonian Institution, Washington, D. C., U.S.A. (USNM), and a severely damaged anterior carapace, missing right cheliped and damaged left chela and carpus, as well as missing second and third left pereopods and damaged right fourth and fifth. Terminology for the description follows that of Forest \& McLaughlin (2000), McLaughlin (2003), and Schram \& Koenemann (2004). One measurement, carapace length, measured from the midpoint of the rostral lobe to the midpoint of the posterior margin of the carapace, provides an indication of animal size. The abbreviations R/V and stn refer to Research Vessel and station, respectively.

\section{Taxonomy}

Family Pylochelidae Bate, 1888

Genus Pylocheles A. Milne-Edwards, 1880

Subgenus Bathycheles Forest, 1987

\section{Pylocheles (Bathycheles) cubensis Ortiz \& Gómez, 1986 (Fig. 1)}

Pylocheles cubensis Ortiz \& Gómez, 1986: 31, figs. 1-9.

Pylocheles (Bathycheles) chacei Forest, 1987: 66, fig. 17a-d.

Type material. Holotype male of Pylocheles cubensis $(19 \mathrm{~mm})$ : Gulf of Cazones, Cuba, mini-submarine Argus, stn 240-39, 570 m, 25 Oct 1983, ANC/IDO.07.1.6.5.047.

Holotype female of Pylocheles (Bathycheles) chacei $(\sim 13 \mathrm{~mm})$ : Turks \& Caicos Islands, N. Haiti, R/V Silver Bay stn 5142, 1952.00’N, 7158.50’W, 640 m, USNM 152529.

Description. Shield (Fig. 1A) slightly longer than broad (but broken and damaged in female), approximately 0.3 longer than posterior carapace; dorsal surface with shallow transverse groove subrostrally. Cervical groove faint to distinct laterally. Posterior median plate broad, moderately well calcified, at least anteriorly. Branchiostegites partially to well calcified dorsally and anteriorly, unarmed. Rostrum (Fig. 1A, C) absent, postocular projections bluntly triangular, unarmed. Lateral projections broadly rounded, produced considerably beyond levels of postocular projections.

Ocular peduncles $0.4-0.5$ length of shield, each with few short setae in distal half of dorsal surface; corneal diameter $0.3-0.4$ of peduncular length. Ocular acicles each as quite small, triangular plate situated slightly mesiad of basal peduncular midline.

Antennular peduncles overreaching distal corneal margins by approximately 0.5 lengths of basal segments. Ultimate segment approximately 0.7 length of subequal penultimate and basal segments; ultimate and penultimate segments each with several scattered setae, basal segment glabrous.

Antennal peduncles with well calcified supernumerary segment; peduncles overreaching distal corneal margins by $0.5-0.8$ lengths of fifth peduncular segments. Fifth and fourth segments each with numerous scat- 
tered fine setae; third segment unarmed and with only few short scattered setae; second segment with dorsolateral distal angle prominently produced, with terminal spine and 3 or 4 small spines on dorsolateral margin, 0-2 small spines basally and spinule on dorsal surface laterally, dorsomesial distal angle unarmed or with small spine. First segment with spine at ventrolateral distal angle.

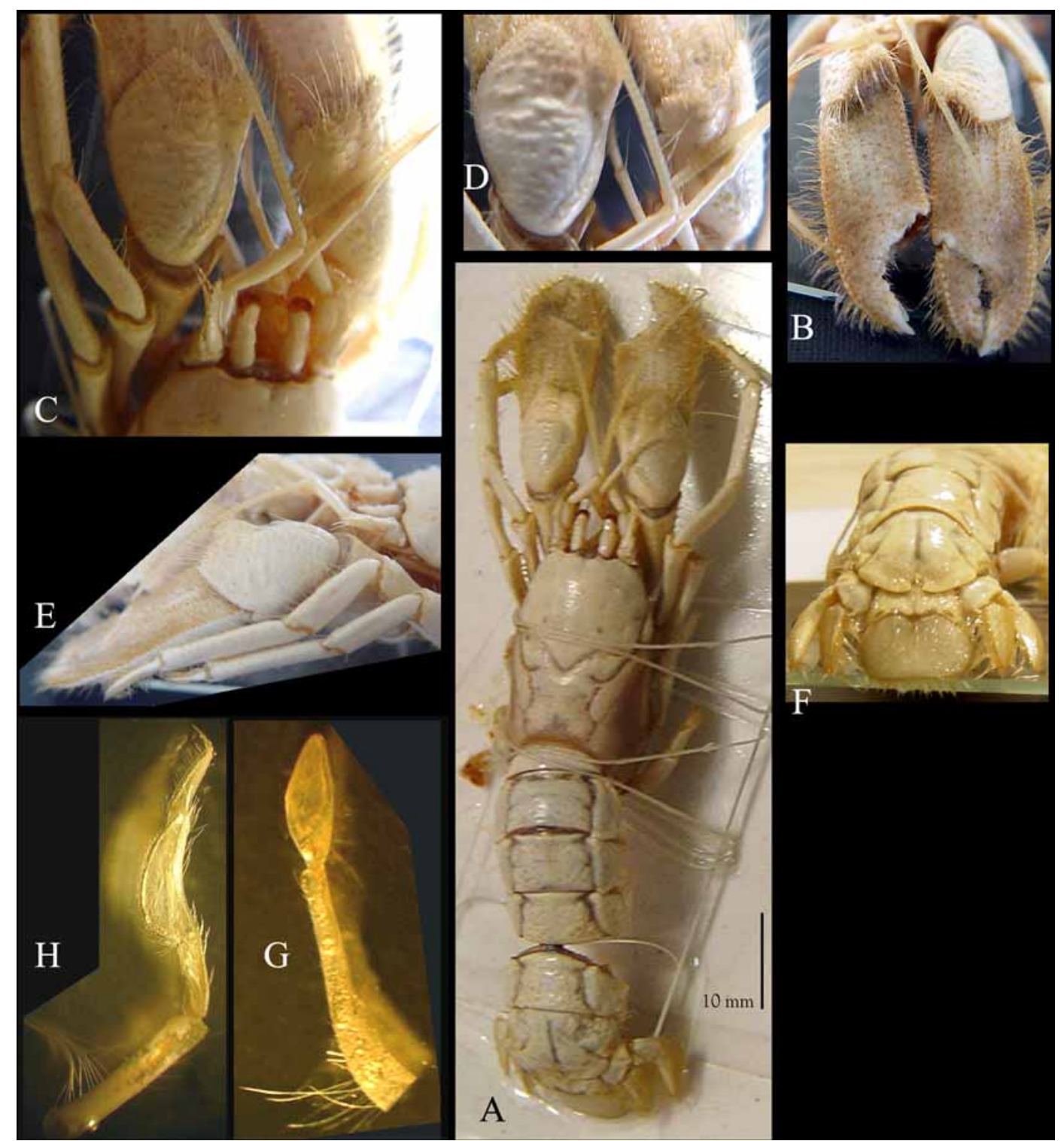

FIGURE 1. Pylocheles (Bathycheles) cubensis Ortiz \& Gómez, 1986, holotype male (19 mm) (ANC/IDO.07.1.6.5.047). A, Dorsal view of whole animal (tied with strings to glass plate); B, chelae and carpi (dorsal view); C, anterior portion of shield, cephalic appendages, carpi of chelipeds, and portion of left second and third pereopods (dorsolateral view); D, enlarged dorsal view of carpi of chelipeds; E, anterior portion of shield, cephalic appendages, left cheliped, and carpi to dactyls of left second and third pereopods (lateral view); F, pleonal tergites 4-6, uropods and telson (dorsal and slightly posterior view); G, right first pleopod (internal view); H, right second pleopod (internal view). (Photographs by M. Ortiz).

Mandible with incisor process well calcified, cutting margin entire. Maxillule with external lobe of endopod obsolete. Maxilla with endopod slightly overreaching distal margin of scaphognathite. First maxilliped with very slender exopod, epipod well developed. Second and third maxillipeds both pediform; second with dactyl approximately 0.7 length of propodus; third maxilliped with well developed crista dentata without accessory tooth, dactyl and propodus varying from approximately equal in length to propodus somewhat 
longer.

Chelipeds (Fig. 1A-D) symmetrical, subrectangular in shape. Left dactyl (right missing) slightly overlapped by fixed finger; dorsomesial margin with row of closely-spaced tubercles; dorsal, mesial and ventral surfaces all with tufts of short to moderately long setae, densest mesially; cutting edge with row of well developed calcareous teeth, terminating in calcareous claw. Dorsomesial and dorsolateral margins of palms each with row of tubercles not concealed by submarginal long setae, dorsal surfaces flat, unarmed, but with covering of sparse tufts of short setae generally forming longitudinal rows; mesial and lateral faces with tufts of moderately long and dense setae dorsally; ventral surfaces with scattered tufts of sparse setae. Carpi roundly subtriangular, each with dorsodistal margin considerably elevated and overhanging proximal margins of chelae; distal margins each cut into 2 lobes by deep incision in mesial 0.3 , division continued posteriorly as distinct, arched depression, margin armed with row of small tubercles laterally and small spines dorsally, not concealed by tufts of long setae; dorsal surfaces (Fig. 1D) with short, transverse, tuberculate ridges in distal 0.2 , larger and more widely-spaced, but less tuberculate, ridges in remaining distal 0.6, becoming much weaker proximally; ventral surfaces unarmed.

Ambulatory legs not overreaching tips of outstretched chelipeds. Dactyls slightly shorter to slightly longer than propodi; dorsal surfaces unarmed and generally glabrous, lateral and mesial faces each with weak longitudinal sulcus, surfaces each with row of moderately long and stiff, but slender setae dorsally and line of short rows of 3-6 or 7 stiff, moderately thick setae adjacent to ventral margin, lateral face also with row of widelyspaced tufts of sparse setae in distal half. Propodi, carpi, meri, and ischia unarmed but with sparse, fine setae on all surfaces.

Pleon (Fig. 1A) with pleura of pleomeres 2-5 distinctly delineated. Sixth pleonal tergite (Fig. 1F) with lateral margins each indented approximately at midlength or slightly more posteriorly and with shallow longitudinal furrow on dorsal surface medianly; terminal margin rounded, unarmed, but notched medianly by deep subquadrate concavity. Protopods of uropods each with prominent spine on posterior margin. Telson as long as broad, unequally divided by transverse suture, with anterior portion slightly narrower than posterior portion; anterior portion with weak depression on either side of midline anteriorly and with ovate area of decalcification at each posterolateral angle (Fig. 1F); posterior portion with lateral margins rounded, terminal margin sometimes with very slight median indentation, and faint median concavity anteriorly, giving bilobed impression, surface with covering of long fine setae, at least posteriorly and marginally.

Male first and second pleopods modified as gonopods. Pleopod 1 (Fig. 1G) with long, moderately slender basal segment and much shorter subovate distal segment. Pleopod 2 (Fig. 1H) with moderately short, stout basal segment; distal segment with semi-articulated distal portion foliaceous and longer than proximal portion.

Color. Unknown.

Habitat. Unknown.

Distribution. Gulf of Cazones, Cuba to Turks \& Caicos Islands, Haiti; 570-640 m.

Remarks. Only one other species of Pylocheles, $P$. (P.) agassizii, is known from the Western Atlantic, and it is immediately distinguished from $P$. (B.) cubensis by the armament of the dorsal surfaces of the chelae, the posterior margin of the sixth pleonal tergite and the structure of the telson. In $P$. (P.) agassizii, the chelae are armed on the dorsal surfaces with numerous tubercles or small spines; the posterior margin of the sixth pleonal tergite is weakly cut into three subequal lobes by small incisions; the anterior portion of the telson is completely calcified; and the posterior portion of the telson is divided into two circular lobes. In contrast, the dorsal surfaces of the chelae of $P$. (B.) cubensis are provided only with rows of tufts of setae; the posterior margin of the sixth pleonal tergite has a prominent, subquadrate median concavity; the anterior margin of the telson has two membranous patches near the outer angles; and the posterior portion of the telson is undivided.

As stated by Forest (1987) for $P$. (B.) chacei, this taxon is morphologically most closely allied to the IndoPacific species $P$. (B.) incisus Forest, 1987 and $P$. (B.) crosnieri Forest, 1987. Forest noted the similarity with 
$P$. (B.) crosnieri in the development of the anterior margin of the shield, or lack thereof, and with $P$. (B.) incisus in the notch in the posterior margin of the sixth pleonal tergite. The dorsal surfaces of the chelae of both Indo-Pacific species are provided only with tufts of setae, as is the case in $P$. (B.) cubensis, thus Forest's (1987) assessment is confirmed. The structures of the mouthparts of $P$. (B.) incisus, illustrated by Forest (1987, fig 16) as representative of the subgenus, agree well with those illustrated by Ortiz \& Gómez (1986) for $P$. (B.) cubensis and those observed in the holotype of $P$. (B.) chacei. The male gonopods of $P$. (B.) cubensis agree more closely with those of $P$. (B.) crosnieri, as illustrated by Forest (1987: fig. 9k, 1), than those of $P$. (B.) profundus Forest, 1987 (ibid.: fig. 9i, j).

Certain discrepancies and inaccuracies appearing in the original descriptions of $P$. cubensis and $P$. (B.) chace $i$ are corrected herein. For $P$. (B.) cubensis, there are some errors in the illustrations and labeling of Ortiz \& Gómez's (1986) figures 8 and 9 of the mouthparts. Specifically, figure 8 is labeled first maxilla when it is actually the maxilla (or second maxilla), the coxal endite is depicted as being trilobed, and the scaphognathite is not illustrated. Figure 9 is labeled second maxilla, but is actually the maxillule (or first maxilla). Additionally, the coxal endite of the first maxilliped (Ortiz \& Gómez 1986, fig. 7) was not illustrated, and while the exopod probably was not omitted, the fact that it is very slender and tends to overlap the endopod was not clearly shown.

The illustration of the holotype of $P$. (B.) chacei (Forest 1987, fig. 17a) although a composite, is reasonably accurate for the cephalothorax and cephalic appendages; however, the accuracy of illustrated portion of carpus of the left cheliped (fig. 17c) can not be verified as there is very little now remaining of that surface. The illustration of the right second pereopod (fig. 17d) is proportionally accurate, but the lines on the lateral face of the dactyl are not corneous spines as they appear, but indications of where the short rows of setae occur. Similarly, the median and dorsal marks on that surface also indicate the positions of the setation described here.

The ocular peduncles of the holotype of $P$. (B.) cubensis are slightly slenderer and the corneas a little smaller than seen in the holotype of $P$. (B.) chacei. Whether these differences reflect size or sex variations is not known at present. The mouthparts are exposed in the damaged anterior cephalothorax of the holotype of $P$. (B.) chacei, and these agree well with the illustrated mouthparts of $P$. (B.) cubensis. However, the dactyl and propodus of the pediform third maxilliped of the former taxon are approximately equal in length, whereas they are subequal in $P$. (B.) cubensis. This again may reflect a size or sex variation as the male is appreciably larger than the female.

\section{Acknowledgements}

This is, in part, a scientific contribution from the Shannon Point Marine Center, Western Washington University. We gratefully acknowledge the invaluable help of the curators in charge of the collections at ANC, who gave us access to the holotype of $P$. (B.) cubensis. Rose A.Gulledge assisted in the preparation of the photographic plate.

\section{References}

Alcock, A. (1905). Anomura. Fasc. I. Pagurides. Catalogue of the Indian decapod Crustacea in the collections of the Indian Museum, 2 i-xi, 1-197. Indian Museum, Calcutta.

Alcock, A. \& Anderson, A.R. (1899). Natural history notes from H.M. Indian marine survey steamer "Investigator", Commander T.H. Heming, R.N. commanding. Series 3, no. 2. An account of the deep-sea Crustacea dredged during the surveying-season of 1897-98. Annals and Magazine of Natural History, (7)3, 1-27.

Bate, C.S. (1888). Report on the Crustacea Macrura dredged by H.M.S. Challenger during the years 1872-76. In: Report on the scientific results of the voyage of H.M.S. Challenger during the years 1873-76. Zoology, 24(52), i-xc, 1-942. 
Benedict, J.E. (1901). Four new symmetrical hermit crabs (Pagurids) from the West India region. Proceedings of the United States National Museum, 23, 771-778.

Boas, J.E.V. (1926). Zur Kenntnis symmetrischer Paguriden. Konelige Danske Videnskabernes Selskabs Skrifter, Biologiske Meddelelser, 5(6), 1-52.

Forest, J. (1987). Les Pylochelidae ou "Pagures symétriques" (Crustacea Coenobitoidea). In: Résultats des campagnes MUSORSTOM. Mémoires du Muséum National d'Histoire Naturelle, Série A, Zoologie, 137, 1-254.

Forest, J \& McLaughlin, P.A. (2000). Superfamily Coenobitoidea. In: Forest, J., de Saint Laurent, M., McLaughlin, P.A. \& Lemaitre, R. The marine fauna of New Zealand: Paguridea (Decapoda: Anomura) exclusive of the Lithodidae. NIWA Biodiversity Memoir, 114, 31-103.

McLaughlin, P.A. (2003). Illustrated keys to the families and genera of the superfamily Paguroidea (Crustacea: Decapoda; Anomura), with supplemental diagnoses of the genera of the Paguridae. Memoirs of the Museum Victoria, 60, $111-144$.

Milne-Edwards, A. (1880). Report on the results of dredging, under the supervision of Alexander Agassiz, in the Gulf of Mexico, and in the Caribbean Sea, 1877, 78, 79, by the United States Coast Survey steamer "Blake", Lieut.-Commander C.D. Sigsbee, U.S.N., and Commander J.R. Bartlett, U.S.N., commanding. VIII. Études préliminaires sur les Crustacés. Bulletin of the Museum of Comparative Zoology, Harvard College, 8, 1-68.

Ortiz, M. \& Gómez, O. (1986). Una nueva especie del género Pylocheles (Anomura Galatheoidea) (sic), de las aguas profundas del sur de Cuba. Revista de Investigaciones Marinas, 7, 31-38.

Schram, F.R. \& Koenemann, S. (2004). Developmental genetics and arthropod evolution: on body regions of Crustacea. In: Scholtz, G. (Ed.) Evolutionary Developmental Biology of Crustacea. Crustacean Issues, 15, 75-92. A.A. Balkema Publishers, Lisse, etc.

Yokoya, Y. (1933). On the distribution of decapod Crustacea inhabiting the continental shelf around Japan, chiefly based upon the materials collected by S.S. "Soyo Maru" during the years 1923-1930. Journal of the College of Agriculture Tokyo Imperial University, 12, 1-236. 